\title{
The Principle of Sufficient Reason and Free Will
}

ABSTRACT: I examine Leibniz's version of the Principle of Sufficient Reason with respect to free will, paying particular attention to Peter van Inwagen's argument that this principle leads to determinism. Ultimately I conclude that Leibniz's formulation is incompatible with free will. I then discuss a reformulation of the Principle of Sufficient Reason endorsed by Alexander Pruss that, I argue, manages to both retain the strength of Leibniz's formulation and remain consistent with free will.

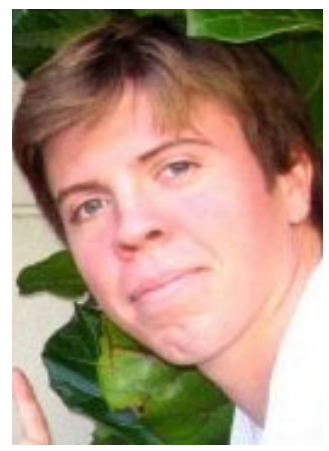

Blake McAllister is a junior philosophy major at Pepperdine University in Malibu, CA. His main areas of philosophical interest include ethics and philosophy of religion. Blake is also an activist for social justice, serving as the president for the International Justice Mission at Pepperdine and cofounding the non-profit, anti-trafficking organization Project Exodus.

$\mathrm{F}$ or many philosophers, the soundness of certain Cosmological arguments, particularly the Argument from Contingency, rises and falls with the Principle of Sufficient Reason. Therefore, if we wish to progress the debate over such arguments, an examination of this principle will prove beneficial. To be clear, I will not be offering a positive argument for the Principle of Sufficient Reason-rather I will assess whether or not this principle is consistent with our intuitions concerning free will.

For the purposes of this paper, I will presuppose the existence of free will. Therefore, if any principle can be shown to be logically incompatible with free will, it will be considered fallacious in some way and in need of revision. My attempt is to evaluate whether or not there is a formulation of the Principle of Sufficient Reason that is both strong enough to bolster Cosmological arguments and an epistemically viable option for philosophers who are committed to affirming free will. With this in mind, I will discuss an influential argument offered by Peter van Inwagen that claims that the Principle of Sufficient Reason entails determinism.

With respect to Van Inwagen's objection, I will argue two main points. First, I will demonstrate that the Principle of Sufficient Reason, as espoused by Leibniz, logically entails determinism. Second, 
I will present a reformulation of the Principle of Sufficient Reason endorsed by Alexander Pruss. I will argue that this reformulation is logically compatible with free will and provides effectively the same support as Leibniz's Principle of Sufficient Reason for arguments in the field of philosophy of religion.

\section{Leibniz's Principle of Sufficient Reason}

In The Monadology, Leibniz lays out the Principle of Sufficient Reason as follows: "we hold that there can be no fact real or existing, no statement true, unless there be a sufficient reason why it should be so and not otherwise, although these reasons usually cannot be known by us." ${ }^{1}$ Leibniz's Principle of Sufficient Reason (LPSR) is incompatible with the existence of brute factsfacts that have no explanation whatsoever; every true proposition must have a sufficient reason for why it is true. In order to get a full understanding of what LPSR entails we must unpack the term 'sufficient reason'.

$Q$ is a sufficient reason for $P$ if and only if $Q$ explains why $\mathrm{P}$ is just so and not otherwise (keep in mind that $\mathrm{Q}$ may be a conjunct constructed of multiple propositions). Thus, no coherent question may be asked about why $\mathrm{P}$ is just so and not otherwise that is not already answered by $\mathrm{Q}$ - for then $\mathrm{Q}$ would require an additional proposition to explain $P$ and $Q$ would not be, by itself, a sufficient reason for $P$.

Note that Leibniz requires a sufficient reason to not only explain why a proposition is just so but also to explain why it is not otherwise. This second qualification implies that a sufficient reason explains more than why $\mathrm{P}$ probably happened, but rather why $\mathrm{P}$ did happen.

For example, imagine that there is a lottery with one million white balls and one green ball. When the lottery is conducted, a white ball is selected. It is not acceptable to say that the sufficient reason for the selection of a white ball, as opposed to a green ball, is that the odds of selecting a white ball were much higher. Although tremendous odds may have been in favor of one side, there remained a real possibility that a green ball could be selected, and therefore we have not, by referencing odds alone, answered fully why a white ball was selected as opposed to a green ball.

Jordan Howard Sobel notes, "A sufficient reason would not merely incline to, but would necessitate, what it would explain... Otherwise one could want a reason why it had operated to its full effect, since what only inclines leaves open the possibility that that to which it inclines should fail to take place." ${ }^{2}$ There cannot be any question why P actually occurred (as opposed to why P probably occurred) given sufficient reason Q. Therefore, a sufficient reason, as defined by Leibniz, must necessitate what it explains.

It is clear from this conclusion that the entailment principle holds for LPSR. The entailment principle states that if $\mathrm{Q}$ explains $\mathrm{P}$, then $\mathrm{Q}$ entails $\mathrm{P}$. By 'entails' I mean that $\mathrm{P}$ is a logically necessary consequence of $\mathrm{Q}$. Thus, we may say that $Q$ serves as a deductive reason for P. ${ }^{3} \quad$ Furthermore, the terms 'sufficient reason' and 'explanation' will be used interchangeably

1. Gottfried Wilhem Leibniz, The Monadology (New York: Forgotten Books, 1898): 32.

2. Jordan Howard Sobel, Logic and Theism: Arguments For and Against Beliefs in God (Cambridge: Cambridge University Press, 2004):

211.

3. Ibid. 
throughout this paper. Hence, saying that $Q$ explains $\mathrm{P}$ is synonymous with saying that $Q$ is the sufficient reason for $P$. With these considerations in mind, we may proceed to the objections offered against LPSR.

\section{LPSR and Determinism}

Many philosophers agree that LPSR is incompatible with free will. The debate between free will and determinism will not be entertained in this paper; rather, I will assume that any principle that eliminates free will is unacceptable. An argument to this end is typically presented in the form of a reductio ad absurdum, which assumes LPSR to be true and then proceeds to demonstrate how the principle entails determinism. Peter van Inwagen offers an influential argument of this nature. If van Inwagen succeeds in demonstrating that LPSR is incompatible with free will, then we must reject LPSR.

Peter van Inwagen begins by making two claims about the nature of contingent propositions:

(1) A contingent proposition cannot explain itself.

(2) A contingent proposition cannot be explained

by a necessary proposition. ${ }^{4}$

Remember that the exacting definition of sufficient reason in LPSR locks us into affirming the entailment principle. With this in mind, we can see that in order for a contingent proposition to explain itself, it must logically entail itself. However, if a proposition logically entails itself, then the proposition is not contingent, but necessary. Thus, (1) appears to be true.

In the same way, any proposition that is logically entailed by a necessary proposition is itself necessarily true. In other words, if a conclusion is deductively drawn from necessarily true premises, then the conclusion is necessarily true. Therefore, (2) is also true-no contingent proposition can be explained by a necessary proposition.

Having established this, van Inwagen has us imagine that there is a Big Conjunctive Contingent Fact (BCCF) that is a conjunction of all true contingent propositions. ${ }^{5}$ Bear in mind that every true contingent proposition is included in the BCCF and that the BCCF is itself contingent. Also, the sufficient reason for the BCCF must explain every part of the conjunct. According to LPSR, the BCCF must have such an explanation-let us call this explanation $G$. Now the question becomes: is $G$ contingent or necessary?

It follows from (2) that $G$ cannot be necessary, for no necessary proposition can explain a contingent proposition and the BCCF is by definition contingent. Therefore $G$ must be a contingent proposition. However, if $G$ is a contingent proposition, then it is a part of the BCCF. Since any explanation of the BCCF must explain every part of it, then $G$ must explain itself.

This, however, is impossible according to (1), which states that no contingent proposition can explain itself. Hence, we are left with only two options: accept that the BCCF has no sufficient reason and LPSR is false, or conclude that the BCCF does not exist because there are

4. Peter van Inwagen, An Essay on Free Will (Oxford: Oxford University Press, 1983): 202-204.

5. Ibid. 
no contingent propositions and thus, eliminate free will. If we assume that banishing free will is unacceptable, then our only option is to admit that at least one proposition does not have a sufficient reason (as defined by Leibniz) and that LPSR is false.

This conclusion becomes clearer upon further examination. Remember that a sufficient reason under LPSR serves as a deductive reason for whatever it explains. The conclusion of a valid deductive argument may only be false if one of its premises is false. Thus, it is logically impossible for any conclusion that deductively follows from necessarily true premises to be false. This means that any proposition that is explained by necessary propositions is itself necessarily true. ${ }^{6}$ It is impossible for contingent propositionsincluding those that describe free choices-to be explained by necessary propositions. Since an infinite regress of contingent propositions is incompatible with LPSR, the only alternative left is determinism.

To better understand how this argument affects the application of LPSR, I will elaborate on an example taken from Quentin Smith. ${ }^{7}$ Smith asks us to examine the actual world, W. For our purposes, there is no relevant distinction between $\mathrm{W}$ and the BCCF discussed by van Inwagen-it is a maximal proposition containing all true conjuncts about the actual world. Bear in mind that in order for free will to exist, $\mathrm{W}$ must be contingent.

Now let us assume for the sake of argument that the sufficient reason for $\mathrm{W}$ is the proposition 'God creates $W^{\prime}$. Is this proposition necessary or contingent? If 'God creates $W^{\prime}$ is necessary, then every part of $\mathrm{W}$-including the choices of persons-is also necessary. Since this is unacceptably deterministic, we are committed to affirming that 'God creates $W^{\prime}$ ' is contingent. According to LPSR, we must now ask for an explanation of why God created W as opposed to some other world or no world at all.

It is clear that we will just end up applying the same reasoning over and over again. The explanation cannot be necessary, for then everything that follows from it must also be necessary, but if the explanation is contingent, then we must ask for yet another explanation. We may keep giving contingent explanations ad infinitum, but eventually we must either come to one that is necessary or admit that there is no further explanation. Even the existence of an infinite regress of explanations would require its own explanation under LPSR. Since it is unacceptable for us to end in a necessary proposition, LPSR must be false.

\section{What Remains of the Principle of Sufficient Reason?}

We have just seen that LPSR entails determinism and is consequently unacceptable. However, must we now throw the Principle of Sufficient Reason out the window? The answer is no. There is a tremendous amount of inductive evidence to support some kind of Principle of Sufficient Reason.

In fact, one could argue that we have the largest amount of inductive evidence possible since no one has ever experienced anything that had no cause or explanation. Furthermore,

6. Sobel, 217.

7. Quentin Smith, "A Defense of A Principle of Sufficient Reason," Metaphilosophy 26, no. 1 \& 2 (1995): 97-106. 
the intuition that everything must have a cause or explanation is being constantly confirmed. Richard Taylor goes as far as to say that the Principle of Sufficient Reason is a presupposition of reason-it is something that "people, whether they ever reflect upon it or not, seem more or less to presuppose." ${ }^{8}$ Given these factors, it is most reasonable to conclude that some formulation of the Principle of Sufficient Reason holds true, even if Leibniz's formulation clearly fails.

Rather than throwing out this principle completely, the best course of action is to reformulate LPSR into the strongest Principle of Sufficient Reason that does not lead to determinism. I will not argue in this paper that we should adopt this principle; instead, I will argue that there is a formulation of the Principle of Sufficient Reason that remains an epistemically viable option for those who are committed to affirming the existence of free will. Let us call this new formulation simply the Principle of Sufficient Reason (PSR).

Ideally, PSR would eliminate the possibility of brute facts. There are several weak versions of the Principle of Sufficient Reason that are compatible with brute facts but are still useful in arguments such as the Argument from Contingency and various Cosmological Arguments. ${ }^{9}$ Many philosophers such as William Lane Craig, William Rowe, and Quentin Smith have discussed such formulations. ${ }^{10}$ However, if we were able to achieve the elimination of brute facts along with the preservation of free will, we would have a formulation that, for all intents and purposes, carries the same weight as Leibniz's original formulation.

Alexander Pruss, in his book, The Principle of Sufficient Reason, offers one such formulation: ${ }^{11}$

(PSR) All contingent facts must have explanarions.

Pruss' formulation is like Leibniz's in that it requires every true proposition to have an explanation-a sufficient reason-for why it is so. However, a key component is absent from PSR that was present in LPSR, namely, the qualification that the sufficient reason must explain why it is not otherwise. Recall that this qualification is the reason why a sufficient reason under Leibniz must necessitate what it explains. Thus, the absence of such a requirement in Pruss' formulation means that there is a significant difference between what qualifies as a sufficient reason under PSR and LPSR.

While sufficient reason under LPSR may accurately be interpreted as a logically sufficient reason, Pruss' formulation uses the term in a much less demanding sense. Pruss explains, "sufficient reason needs to be understood not as 'necessitating reason' but as 'sufficient explanation,' where we understand that a causal account is always sufficiently explanatory, even

8. Richard Taylor, Metaphysics (Englewood Cliffs, NJ: Prentice-Hall, Inc., 1992).

9. Such formulations typically only require a sufficient reason for the existence of any being rather than a sufficient reason for any positive fact whatsoever.

10. William Lane Craig, "The Cosmological Argument," in The Rationality of Theism, ed, Paul Copan and Paul K. Moser (London: Routledge, 2003): 114-115 ;William Rowe, "The Cosmological Argument," Nous 5, no. 1 (1971): 56 ;Smith, "A Defense of a Principle of Sufficient Reason," 97-106 ; Alexander R. Pruss, The Principle of Sufficient Reason (New York: Cambridge University Press, 2006).

11. Alexander R. Pruss, The Principle of Sufficient Reason (New York: Cambridge University Press, 2006). 
when indeterministic." ${ }^{12}$ Hence, if you have named the cause of the event, then you have sufficiently explained it.

With this new definition of 'sufficient reason' we may reexamine claims (1) and (2) of van Inwagen's argument. Both of these claims are essential to the success of van Inwagen's objection, therefore, if either claim is false for PSR, the objection fails and PSR is compatible with free will. Although there is formidable reasoning for why we should reject both of these claims, ultimately it is only necessary that we reject one claim in order to adequately defend PSR.

The truth of (2) - a contingent proposition cannot be explained by a necessary propositionis determined by whether or not we affirm the entailment principle, i.e. if $\mathrm{Q}$ explains $\mathrm{P}$, then $\mathrm{Q}$ entails $P$. If the entailment principle holds, then in order for a necessary truth to explain a proposition, it would have to logically entail that proposition, and any proposition that is logically entailed by a necessary truth must itself be necessary. Thus, no contingent proposition may be explained by a necessary proposition. However, if we reject the entailment principle, then there is no reason why a contingent proposition may not be explained by a necessary proposition.

In order to reject the entailment principle for PSR we must provide an example of an explanation that serves as a satisfactory explanation under PSR and is indeterministican explanation in which $\mathrm{Q}$ explains $\mathrm{P}$ but the existence of $Q$ is logically compatible with the non-existence of P. Examples of this nature are not difficult to find. For instance, having flipped the light switch is a satisfactory explanation for the lights turning on under PSR. However, we can certainly imagine a situation in which the light switch is flipped but the lights do not come on-perhaps there was no power or the light bulbs had burned out. This example is a situation in which $\mathrm{Q}$ (flipping the light switch) explains $\mathrm{P}$ (the lights come on) but the existence of $Q$ (the switch is flipped) is compatible with the non-existence of $\mathrm{P}$ (the lights do not come on). This being the case, we may reject the entailment principle for PSR and consequently, reject (2).

The entailment principle also determines the truth of (1) - a contingent proposition cannot explain itself. The argument in support of (1) stated that in order for a proposition to explain itself, it must logically entail itself, but any proposition that logically entails itself is necessary. Therefore, no contingent proposition can explain itself. This line of reasoning clearly presupposes the entailment principle. As we have already seen, it is not necessary under PSR that an explanation entail what it explains, thus, a proposition may explain itself without logically entailing itself. Consequently, there does not appear to be any good reason why a contingent proposition cannot explain itself, given the less demanding definition of 'explanation' used for PSR. It is at least logically possible for a selfexplanatory contingent proposition to exist.

Pruss offers an example of what he views to be a self-explanatory contingent proposition. ${ }^{13}$ A proposition is self-explanatory when you cannot understand the proposition without also understanding the explanation for why it is true. Pruss argues that free actions in a Jamesian libertarian view are both contingent 
and self-explanatory in this sense. For instance, the proposition 'God freely chose A for R' fully explains why God freely chose A for R. The fact that God freely chose means that He was not forced to extend his will in one direction or another, but rather the He freely chose to extend his will in the direction of A. In this way, simply understanding the proposition 'God freely chose A for $\mathrm{R}^{\prime}$ gives you enough information to determine the explanation of the propositionnamely, it was a free act on the part of God, and $\mathrm{He}$ freely chose to extend it in the direction of $\mathrm{A}$.

Not every free action, however, qualifies as a self-explanatory contingent proposition. For example, take the proposition 'John freely chose A for R'. While we have an explanation for why John freely chose A for R in the fact that it was a free choice, the proposition is not fully selfexplanatory.

In order to be a self-explanatory proposition there may be no fact about the proposition that is not already explained by the proposition itself. Asserted as a part of the proposition 'John freely chose A for R' is the fact 'John exists', and the explanation of this fact is not contained within the proposition 'John freely chose A for R'. Since John is a finite being, his existence is contingent and we must look outside of him-to his parents for example-to find the sufficient reason for his existence. The explanation for John's existence is not contained within the proposition 'John freely chose A for R'; therefore, the proposition is not self-explanatory.

At least one kind of proposition can bypass such problems, and that is the free action of a necessary being. ${ }^{14} \mathrm{~A}$ necessary being exists in every possible world; therefore, the explanation of such a being's existence is contained within the concept of a necessary being. Given the traditional theistic conception of God as a necessary being, the fact 'God exists' is sufficiently explained by the proposition 'God freely chose A for $\mathrm{R}^{\prime}$ - understood within the concept of God is His necessary existence. Through the free action of a necessary being, Pruss has provided us with an example of a self-explanatory contingent proposition and grounds for rejecting (1).

It appears we might have good reasons to find both claims (1) and (2) false for PSR. Bear in mind that it is only necessary to show that either (1) or (2) is false-not that both are false. As a result, it is reasonable to conclude that Van Inwagen's objection fails to show that PSR is incompatible with free will. I have not provided, nor tried to provide, an extensive positive case for why we should accept PSR. What I have tried to do is to demonstrate that PSR does not logically entail determinism. In this way, PSR-a considerably strong version of the Principle of Sufficient Reason, given that it eliminates the possibility of brute facts-remains a viable option for philosophers to consider.

\section{The Significance of PSR}

Contemporary discussions involving the Principle of Sufficient Reason are often found in the field of philosophy of religion. Specifically,

14. There is a heated debated between philosophers as to whether the concept of a necessary being is logically coherent. However, most agree that if it is possible for a necessary being to exist, then a necessary being must exist. Therefore, if it were the case that a necessary being made a free choice, the explanation of that being's existence could be a priori demonstrated from the very concept of the necessary being. 
the Principle of Sufficient Reason becomes applicable in various Cosmological arguments including the Argument from Contingency. The main significance of PSR as opposed to other formulations is that it remains strong enough to support arguments for the existence of God. Pruss explains, "as applied to the Big
Conjunctive Contingent Fact...the principle shows the existence of a necessarily existing being that is the first cause."15 Thus, we now have a formulation of the Principle of Sufficient Reason that is compatible with free will and still retains its value with respect to traditional arguments for the existence of God.

15. Ibid, 185. 